\title{
Leaving Work, Leaving Home: Job Loss and Socio-geographic Mobility in Canada
}

Nicole Denier

McGill University

\section{Motivation and Questions}

- Job loss is a persistent feature of the Canadian labour market that is associated with earnings and income losses ${ }^{1}$, and interruption in the educational attainment of one's children ${ }^{2}$.

- To date, very little research has examined how job loss relates to demographic processes, like internal migration.

- Moving is a costly and often stressful event that may bring about substantial changes in one's surroundings. Studying mobility following job loss may provide insight into mechanisms that lead to deterioration in well-being associated with job loss.

(Q1) Is job loss associated with geographic mobility in Canada?

(Q2) Does job loss trigger entry into materially deprived neighbourhoods?

\section{Background}

Lifecycle Theory of Mobility
Moving is a response to changes in housing demand over the lifecycle,
associated with changes in family composition, school completion and associated with changes in family composition, school completion and career mobility. Job loss so far has been a neglected event in the housing lifecycle.

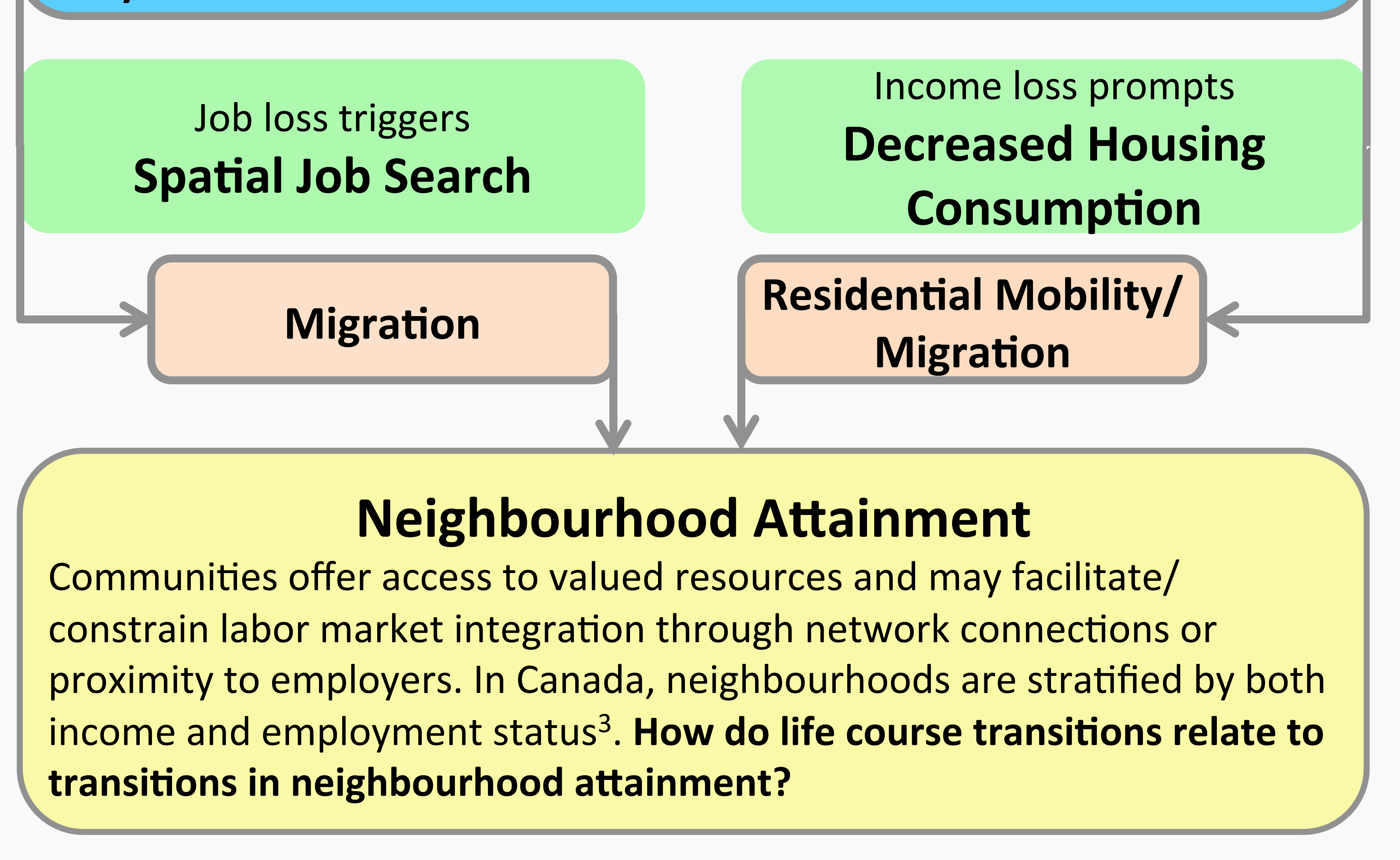

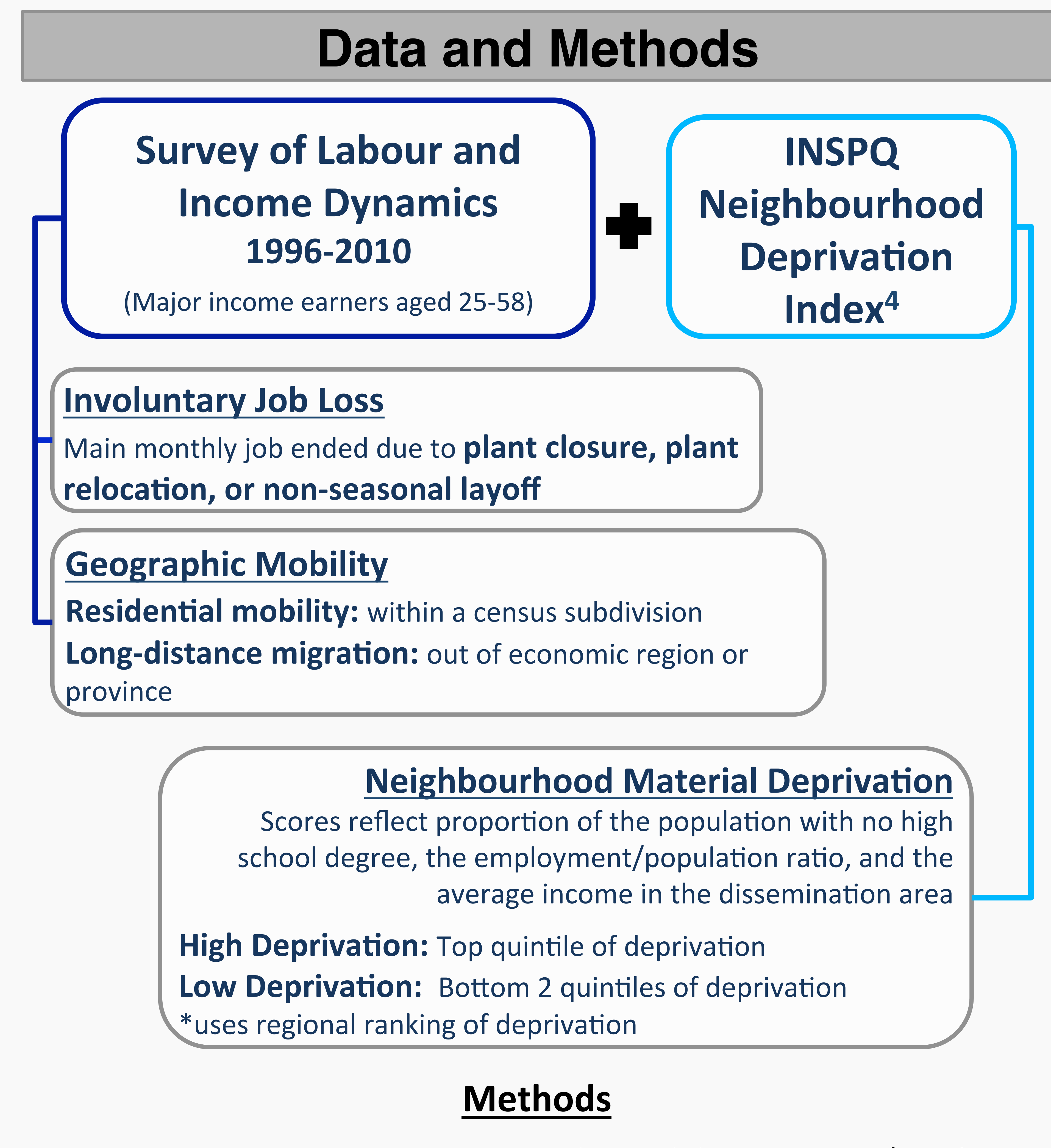

- Logistic regressions predict geographic mobility and entry/exit from high and low deprivation areas.

- Covariates: age, age squared, gender, household composition, marital status, home ownership, urban residence, province, and household income measured at time $t-1$.

\section{Findings}

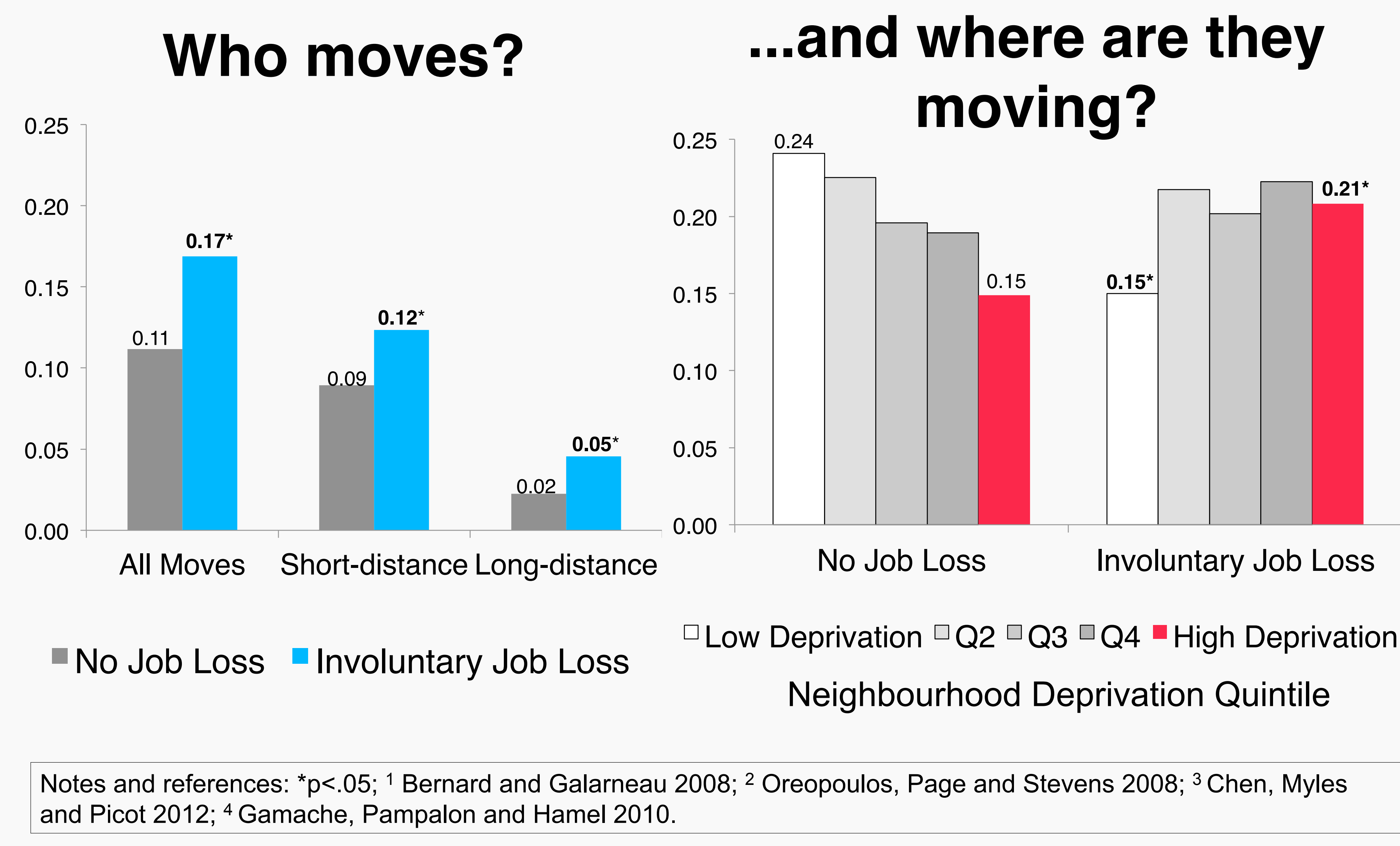

\section{Findings}

Lifecycle stage and resources do little to explain increase in mobility associated with job loss.

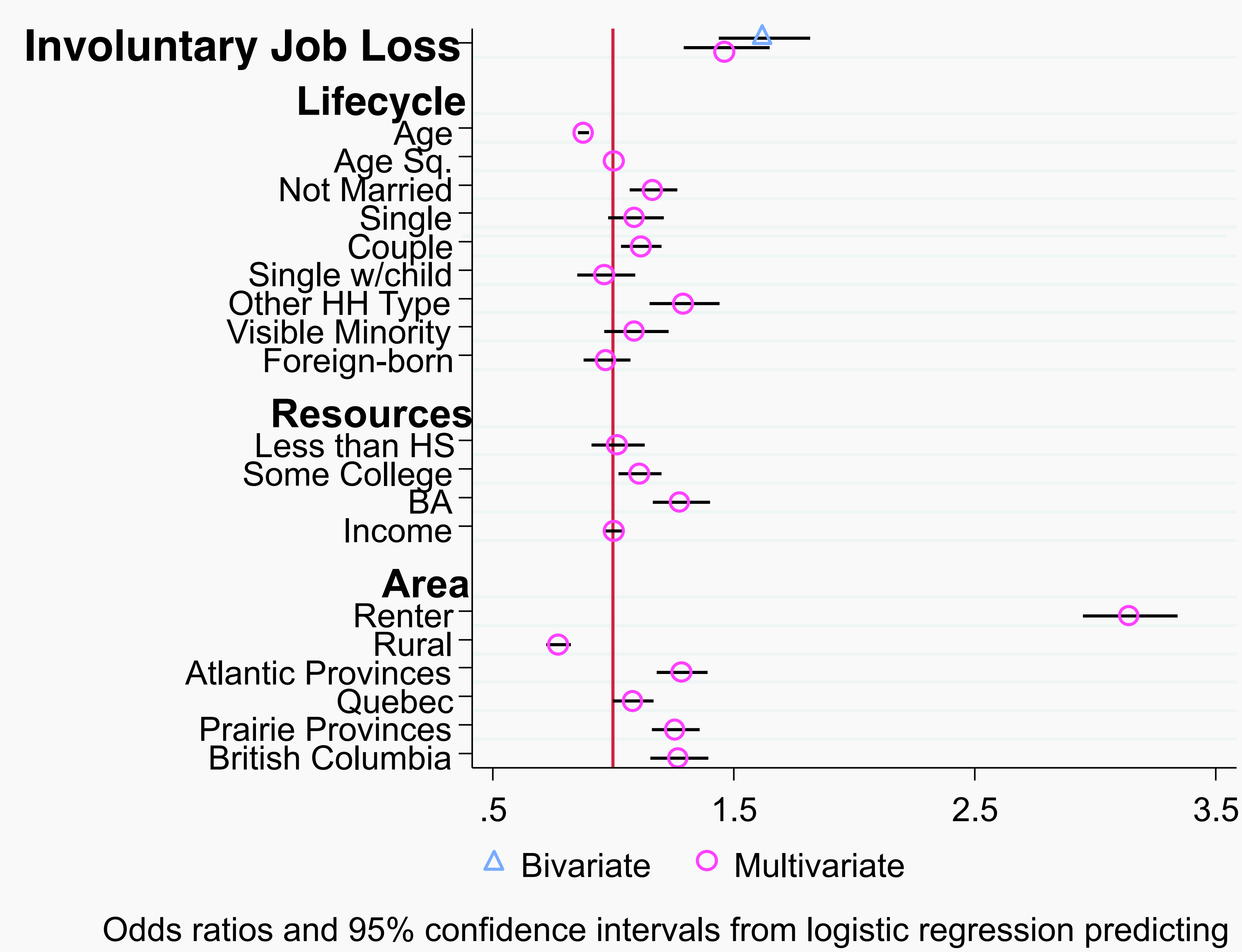

Odds ratios and $95 \%$ confidence intervals from logistic regression predicting mobility between $t-1$ and $t$.

Is job loss associated with selective mobility?

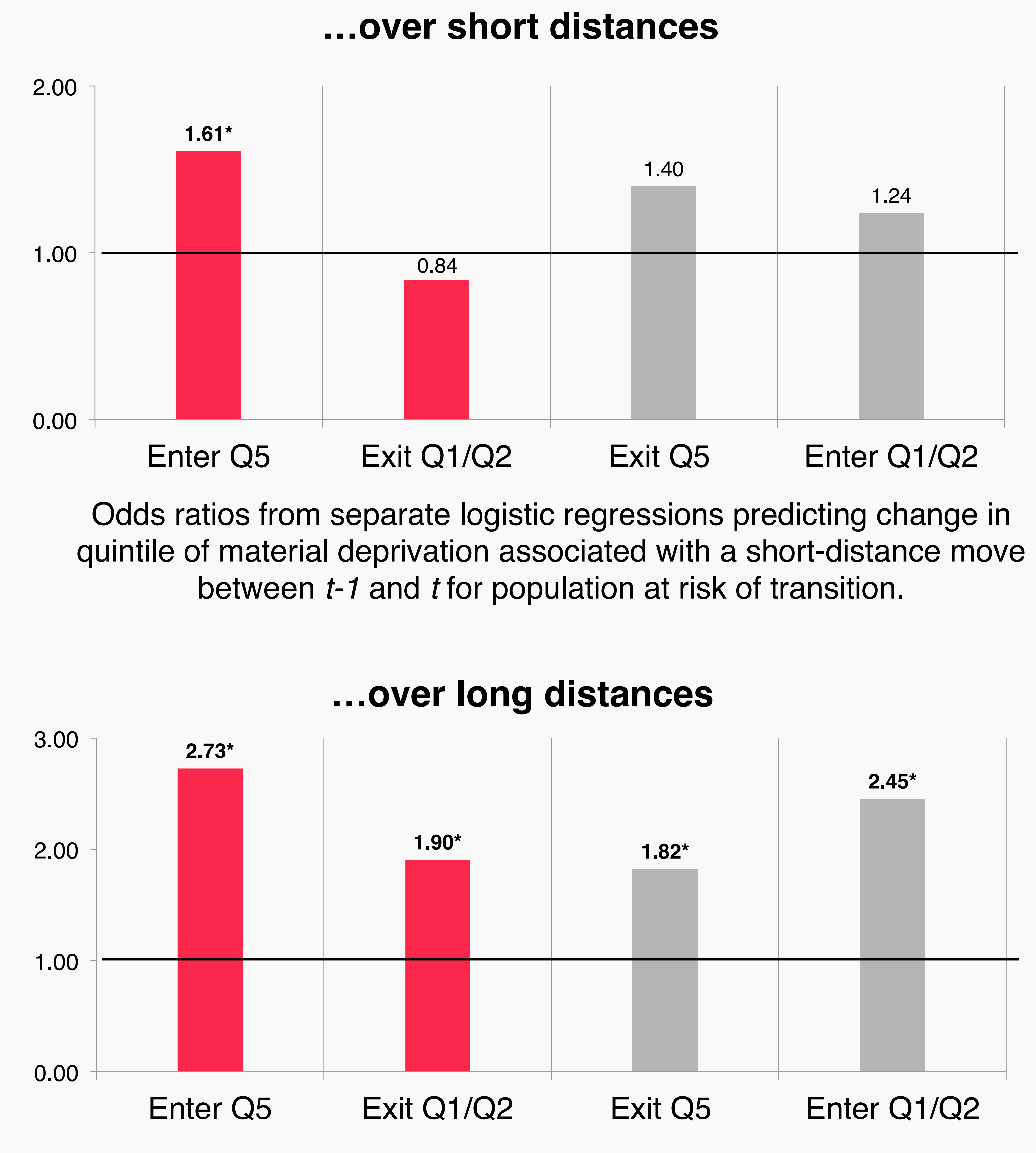

Odds ratios from separate logistic regressions predicting change in quintile of material deprivation associated with a long-distance move
between $t-1$ and $t$ for population at risk of transition. 